\title{
1 Evaluating how lethal management affects poaching of Mexican wolves
}

2 Naomi Louchouarn ${ }^{1 *}$, Francisco J. Santiago-Ávila $^{1 *}$, David R. Parsons ${ }^{2}$, Adrian Treves $^{1}$

$3 \quad{ }^{1}$ Nelson Institute for Environmental Studies, University of Wisconsin-Madison

$4 \quad{ }^{2}$ Project Coyote Science Advisory Board

$5 \quad$ *Eual first co-authors 
7

\section{7}

Abstract

Despite illegal killing (poaching) being the major cause of death among large carnivores globally, little is known about the effect of implementing lethal management policies on poaching. Two opposing hypotheses have been proposed in the literature: implementing lethal management may decrease poaching incidence ('killing for tolerance') or increase it ('facilitated illegal killing'). Here, we report a test of the two opposed hypotheses that poaching (reported and unreported) of Mexican grey wolves (Canis lupus baileyi) in Arizona and New Mexico, USA, responded to changes in policy that reduced protections to allow more wolf-killing. We employ advanced biostatistical survival and competing-risk methods to data on individual resightings, mortality and disappearances of collared Mexican wolves, supplemented with Bayes Factors to assess strength of evidence. We find inconclusive evidence for any decreases in reported poaching. We also find strong evidence that Mexican wolves were $121 \%$ more likely to disappear during periods of reduced protections than during periods of stricter protections, with only slight changes in legal removals by the agency. Therefore, we find strong support for the 'facilitated illegal killing' hypothesis and none for the 'killing for tolerance' hypothesis. We provide recommendations for improving the effectiveness of US policy on environmental crimes, endangered species, and protections for wild animals. Our results have implications beyond the USA or wolves because the results suggest transformations of decades-old management interventions against human-caused mortality among wild animals subject to high rates of poaching.

Keywords: Conservation, endangered species, poaching, policy signal, survival analysis, large carnivore, Mexican wolf, Canis lupus baileyi 


\section{Background}

31 Human-caused mortality is the major cause of death among large, terrestrial, mammalian carnivores worldwide [1], including the USA [2-5]. Anthropogenic mortality has precipitated the decline and extirpation of carnivore populations worldwide both indirectly and directly through the often coinciding threats of habitat loss and degradation, prey depletion, and killing [6]. Indeed, reported and unreported poaching is the major form of human-caused mortality for large carnivore populations in several regions [7,8], including five U.S. wolf populations [4]. Such mortality raises individual and societal concerns because poaching is an environmental crime, harms individual animals, and undermines restoration and conservation efforts. concealed, illicit killing rates has recently been transformed by two analyses that used data that

42 had previously been ignored. Liberg et al. [7] estimated the hazard rate of cryptic (i.e., unreported or concealed) poaching by considering slow-downs in population growth and accounting for the disappearances of marked grey wolves in Scandinavia. Similarly, Treves et al.

45 [5] re-calculated the risk of poaching relative to other causes of death by considering missing, marked animals, which had previously been excluded from analyses under an erroneous

47 assumption that marked animals that disappeared would have died of similar causes as those marked animals found dead. Therefore, investigators can now better estimate heretofore underappreciated variables that are essential to understanding population dynamics and individual

50 animal life histories. However, the latter study admittedly did not directly estimate poaching,

51 instead using estimates from other populations (Scandinavia and Wisconsin) as multipliers to

52 indirectly quantify cryptic poaching, and did not measure policy effects on poaching or consider 
53 time to exposure of wolves to policies. Its objective was strictly to estimate the risk of poaching

54 in a population regardless of policy period. Therefore, here we propose an important advance to

55 estimate the relationships between policy interventions and fates of marked carnivores, while

56 controlling for spatiotemporal covariates. We test opposed hypotheses from the literature

57 explained next.

58

59 The scientific literature has recently addressed the question of if and how policies may influence the hazard and incidence of poaching. The usual assumption (despite lack of empirical evidence)

61 is that some predator-killing (e.g.: government permits for killing or public hunting seasons)

62 might increase tolerance for a species (and thus reduce poaching); an argument first articulated in

63 federal court in 2006 and summarized more generally in $[9,10]$. We call this first hypothesis

64 'killing for tolerance', which predicts legal killing will reduce poaching through the following

65 mechanism: legalizing or liberalizing killing of controversial species will lead would-be

66 perpetrators to desist from poaching because of increased tolerance for the species or approval

67 for protectionist policies. Early tests of this notion of 'killing for tolerance' include [11-17].

68 Olson et al. [11] examined correlations between documented (i.e., reported) poaching of

69 Wisconsin's wolves and management policies between 2003-2011. They suggested that the

70 incidence of known poaching events was inversely related to the proportion of each year with

71 state management associated with liberalized killing periods, and hypothesized that frustration

72 with protections for wolves led to increased poaching. Studying the same population albeit with

73 more sophisticated modeling of demographic processes, Stenglein et al. [18] estimated an

74 additional mortality of $4 \%$ was necessary to explain the observed slow-down in the population's

75 annual growth rate within that same time period. These early tests of the killing for tolerance 
hypothesis attribute rates of poaching and population dynamic changes to illegal actions

77 motivated by inconsistent management and protections for controversial wolves. By contrast,

78 Chapron \& Treves [15] reported serial slow-downs of wolf population growth during 6 non-

79 consecutive policy periods in Wisconsin and Michigan from 1995-2012, which seemed attributable to unreported wolf-killing. They proposed an explanation we refer to as 'facilitated illegal killing'. Three social scientific studies published between 2013 and 2015 [12-14] examined attitudes towards wolves in Wisconsin and found that tolerance decreased as wolf killing was progressively liberalized or intention to poach wolves increased as wolf-killing was progressively liberalized from 2003-2013. Considering such evidence, the alternative hypothesis of 'facilitated illegal killing' suggests that liberalized killing might decrease the value of wolves to would-be perpetrators of poaching, or decreasing the risk of being caught [15]. A 2019 reanalysis using the methods proposed below found liberalized killing policy periods in Wisconsin, USA (1979-2012), were associated with increases in hazard and incidence of wolf disappearances that outweighed by five-fold any decreases in reported poaching, undercutting the 'killing for tolerance' hypothesis [19]. Despite the lack of a clear causal connection between

91 attitudes and poaching, the study describe here tries to establish a closer mechanistic link

92 between policies and poaching behavior. In sum, two published hypotheses make opposed 93 predictions about the rates of poaching in relation to policies for liberalizing legal killing of 94 controversial species.

96 Other research linking wolf mortality to population growth rates in a hunted Finnish population

97 found increases in population size were positively associated with increases in poaching [8].

98 Using generalized linear models focused on predictors of poaching, the same team later found 
99 the number of legally hunted wolves both across the country and at the local scale was associated

100 with a decrease in the probability of poaching, while increases in the number of wolves that

101 could be legally killed (the 'bag limit') were associated with increases in the probability of

102 poaching [20]. Additionally, the authors suggest that declines in poaching following higher

103 levels of legal hunting might be an artifact of a decrease in the individual wolves exposed to

104 poaching [20, p. 7]. They concluded that "tolerance for carnivores cannot be promoted by legal

105 hunting alone, so more comprehensive conservation efforts are needed" $[8,20]$.

107 The most recent publication on this topic for grey wolves in Scandinavia [21], suggested that more territorial breeding individuals removed legally, fewer such animals disappeared

109 (presumably poached), but their analysis has been questioned on the grounds of inappropriate statistical analyses and incomplete treatment of the apparent rise in disappearances during years 111 with legal wolf-killing [22]. and assumptions made in all three studies from the U.S. upper Midwest and Nordic countries time wolves were exposed to liberalized killing policies that changed 12 times between 1995-

1172012 in the US and several times in the Nordic countries [15,24]. Here we build on these

118 analyses by including the amount of time that radio-collared wolves were exposed to liberalized 119 killing policies to re-estimate hazard and incidence of poaching. 
121 Indeed, a simple reduction in poaching may not be equivalent to 'tolerance'; that is, greater

122 acceptance of wolves on the landscape. The 'killing for tolerance' hypothesis suggests a

123 cognitive mechanism that implies something broader than a reduction in poaching, which is only

124 one anthropogenic endpoint affected by tolerance. However, poaching is not the only human

125 behavior affected by tolerance causing wolf mortality. Human tolerance would arguably affect

126 other anthropogenic endpoints such as legal killings or (in this particular population) final

127 removals (e.g., through increased legal killings by citizens or requests for action to government

128 agents leading to increased mortality, similar to that found in Scandinavia [20]). Thus, any

129 comprehensive exploration of 'tolerance' affecting wolf mortality should examine the

interactions between the different anthropogenic endpoints and their resulting incidences.

132 Opposing views of the relationship between legal killing and poaching of wolves can be tested if

133 we analyze individual wolf survival in relation to the timing and duration of their exposure to

134 periods with different policies for legal killing. Here we will test the specific hypothesis that

135 rates of hazard and incidence of mortality or disappearance of wild Mexican grey wolves (Canis

136 lupus baileyi) in Arizona and New Mexico, USA, changed after policies altered the legality of

137 killing or harassment of Mexican wolves by the public and government agencies. Table 4

138 provides predictions for the two response variables of hazard ratios and competing risk

139 subhazard ratios. There has been no research on the opposing hypotheses of "killing for

140 tolerance" or "facilitated illegal killing", within this population. Such a test is particularly

141 important as Mexican wolves are a highly endangered subspecies of grey wolves. Previous

142 estimates [4] indicate poaching rates in this population have been high and under-estimated by

143 traditional methods. 
145 The subspecies was functionally extinct in the USA by the 1970s due to extermination efforts by 146 state, federal, tribal and private actors [25]. A captive breeding program began in 1977, and the

147 US government began releasing Mexican wolves to the Blue Range Wolf Recovery Area in 148 southern Arizona and New Mexico in 1998. From 1998 to 2016, all Mexican wolves released to

149 the recovery area were fitted with a radio collar and were closely monitored $(\mathrm{n}=279$ radio150 collared). Here we examine the survival and disappearances of adult marked Mexican wolves

151 before, during, and after two policy periods, one in 2005-2009 and another starting in 2015, that

152 liberalized killing or removal of wolves by government or private actors.

154 We examine data on radio collared animals using competing risk analyses that allow the modelling of hazards and incidences of multiple fates (i.e., various causes of death or lost to 156 monitoring; endpoints, hereafter) while controlling for multiple covariates. We model exposure 157 time to policy changes. This analysis allows us to make inferences beyond the cursory examination of compensatory mortality causes due to changes in policy, to examine how policies

159 might impact an individual wolf's probability of succumbing to a cause of death. Furthermore, 160 using a competing risks analysis allows us to include disappearance as an endpoint which is 161 crucial given that prior work shows that censoring LTF led to systematic under-estimates of 162 poaching in other grey wolf populations [4,19]. The results of this analysis can provide 163 recommendations for improving the effectiveness of US policy on environmental crimes, 164 endangered species, and protections for wild animals. Therefore, our analyses have implications 165 beyond the USA or wolves because the methods promise to transform scientific understanding of 
166

167

168

169

170

171

172

173

174

175

176

177

178

179

180

181

182

183

184

185

186

187

processes and patterns in human-caused mortality among wild animals subject to high rates of unregulated killing.

\section{Methods}

Data Collection and Preparation

We analyzed data acquired from the Department of Interior U.S. Fish \& Wildlife service (USFWS) Mexican Wolf Recovery Program (MWRP) and their Office of Law Enforcement (OLE) in separate but overlapping datasets on (marked (hereafter collared), monitored Mexican wolves in the wild. The MWRP survival data include the monitoring history for all collared and monitored adult Mexican wolves in the wild since the beginning of the recovery program, 29 March1998- 31 December 2016; $\mathrm{n}=279$ (monitored wolf pups were excluded from this dataset).

Because of the small wild population size and the captive breeding program, the majority of wolves in the Mexican wolf recovery area were collared or marked for monitoring. Only wildborn individuals that eluded capture remained unmonitored. Therefore, our analysis has the benefit of reducing (but not completely eliminating) a common bias in monitored animal studies when the marked subsamples are non-random, unrepresentative samples of the wild population, and may not have the same mortality risk as unmarked individuals [26-30].

\section{The MWRP survival data contain the following individual covariates we used in our statistical} analysis: monitoring start date, sex, and endpoint (i.e., end of monitoring time by: cause of death, lost to follow-up LTF, or removal by agency action). The endpoint 'removal' by agency action typically involved USFWS live-capture of a wolf from the wild followed by either placement in 
captivity or killing. The endpoint of LTF occurred when the telemetry equipment affixed to a wolf in the wild stopped functioning and the collar was never recovered. This could happen from mechanical/battery failure or destruction by external causes such as humans. Some wolves had multiple collars during their monitoring history as a result of recapture and recollaring. The vast majority of monitored time intervals $(87.6 \%)$ were obtained using VHF collars, while the remaining $13 \%$ of monitored intervals were obtained with GPS collars. In our data, the average amount of time to LTF for wolves wearing VHF collars was 621 days, with a range of 7 to 3,079 days. The average battery life of a VHF radio collar is about 1,095 days, but wolves were often recollared. Only one individual disappeared while wearing a GPS collar, and this individual went LTF after 169 days. For recovered collars, cause of death was estimated by USFWS using standard methods following necropsy and radiography.

For each of the 279 wolves in the MWRP survival data (1998-2016), we estimated the time between collaring (monitoring start date) and endpoint in days ( $\mathrm{t}$ ), but we did so differently for surviving, dead, and LTF endpoints. We censored surviving wolves at the end of our study period. For LTF endpoints, we used the date of last telemetry contact. Inclusion of LTF as a separate, explicitly modelled endpoint was crucial for our inferences because of prior work showing that censoring LTF led to systematic under-estimates of the proportion and hazard of poaching in other grey wolves $[4,19]$. Some wolves might have lived on for a time after their telemetry contact was lost, so LTF represents a systematic under-estimate of survival and hence of our parameter, t. We address the consequences and magnitudes of that bias in the Results. For our 'mortality' and 'agency removal' endpoints, we estimated t for wolves monitored by telemetry until death and the date of final removal to captivity by agency action, respectively. 
213 Mortality endpoints obtained from the MWRP survival data were classified only as 'human' or

214 'natural' in our first analysis step. Natural, used by both MWRP and OLE presumably meant

215 nonhuman cause of death. The human-caused endpoint was identified in the MWRP data as

216 mortality with 'likely and known human causes', without a more specific cause of death (e.g.,

217 vehicle collision, poaching). In the second analysis step, we turned to the OLE data, which

218 categorized human-caused mortality by the following causes of death: vehicle collisions, trap,

219 gunshot, blunt force trauma, 'unknown' or 'other'. Using this data, we classified human-caused

220 deaths as either poached (trap, gunshot, blunt force trauma) or non-criminal (vehicle collisions,

221 'unknown', 'other' with no evidence of human intent). We used all human-caused deaths

222 recorded up to and including 31 December 2016.

223

224 We focused our analysis on a time-varying covariate for policy-period (the policy intervention or

225 IV in Table 4). Policy-period was binary for period of liberalized wolf-killing ('1') or stricter

226 protections ('0') following exact policy change dates. Our policy covariate changed from 0 to 1

227 on October 10, 2005 when Standard Operating Procedure 13.0 (SOP 13) 'Control of Mexican

228 wolves', was implemented by the Mexican Wolf Blue Range Reintroduction Project Adaptive

229 Management Oversight Committee (AMOC) and changed back to 0 on December 2, 2009 (Table

230 1). SOP 13 liberalized wolf killing ('1') by establishing a "three-strikes" policy requiring the

231 permanent removal of wolves implicated in three instances of predation on domestic ungulates

232 during a one-year period. During SOP13, removals of wolves more than doubled relative to the

233 previous seven years [31]. The policy was challenged in court and terminated by a federal judge

234 on 2 December, 2009. However, a subsequent change in policy would again liberalize the killing 
of wolves. Thus, our policy covariate changed from 0 to 1 again from 16 January 2015 to 31

December 2016, which is the last date of our Freedom of Information Act data request (and the end of our study period). On 16 January 2015, the USFWS implemented a modification to the 1998 Endangered Species Act (ESA) 10j rule that expands the area where Mexican wolves can be released, allows permitted private entities to kill wolves on non-federal land if wolves are deemed to be a danger to domestic animals, and allows killing by government agents on private and state lands if wolves cause unacceptable predation on big game animals.

We also modeled season as a time-dependent covariate using an October-March (winter) and April-September (summer) split, because elsewhere season is known to mediate mortality in wolves $[8,19,32,33]$. For example, preliminary analysis of a population of Wisconsin wolves revealed winter periods were associated with increases in the hazard and incidence of various endpoints (LTF, poaching, natural death) and at different rates [19]. To model both timedependent covariates (policy and season), we created splits in each collared wolf's monitoring history. We refer to these splits as 'spells' given they refer to briefer periods within an individual's monitoring time (see Table 1). In selecting the covariates of interest, we are following best practices of having at least 10 endpoint events per covariate [34-36]. We have therefore excluded from our models any covariates unless they are essential to control.

\section{Nuisance variables are unlikely to confound our analyses as we discuss next. A hypothetical} nuisance variable would have to not only correspond to the various changes in policy (2-3) but also be widespread across both NM and AZ across multiple jurisdictions (tribal, state, federal, county lands), and affect multiple independent adult wolves in packs occupying virtually 

hypothetical case).

exclusive home ranges. That leaves a climatic event or other widespread biotic event such as a disease with more than one change (to correspond with the policy changes of interest). We have searched both USFWS program documents and the scientific literature and have found no evidence of changes in environmental events or onsets of disease. Moreover, the covariates that may impact our hypotheses would need to affect the poaching, LTF and legal killing risks.

Instead, environmental changes that may covary with the policy may in fact show changes to the 'natural' endpoint hazard and incidence, while perhaps affecting the changes in incidence of our anthropogenic endpoints (through endpoint interactions, see below) but not their hazards.

Table 1. Example of monitoring history of a hypothetical wolf ID, broken up into spells for the integration of time-dependent covariates. We use "analysis time" for the time intervals and order of spells, as covariates change (either policy or season). The endpoint categorical variable is only

\begin{tabular}{|c|c|c|c|c|c|}
\hline wolf ID & $\begin{array}{l}\text { analysis time } \\
\text { when spell } \\
\text { begins }\end{array}$ & $\begin{array}{l}\text { analysis time } \\
\text { when spell } \\
\text { ends }\end{array}$ & policy & season & endpoint \\
\hline MX1209 & 0 & 57 & 1 & 1 & \\
\hline MX1209 & 57 & 140 & 1 & 0 & \\
\hline MX1209 & 140 & 350 & 0 & 0 & 2 \\
\hline
\end{tabular}


274 We employed endpoint-specific hazard and subhazard models in a competing risk framework,

275 which are extensions of survival (or 'time-to-event') analyses, and a special case of multi-state models [37]. Survival analyses estimate the probability of observing a time interval from the start

277 of monitoring (in our case, release to the wild with a functioning transmitter) to an endpoint, T, 278 greater than some stated value $t, \mathrm{~S}(\mathrm{t})=\mathrm{P}(\mathrm{T}>t)$ within a specified analysis time (our study period 279 above). These techniques allow for calculating the (endpoint-specific) hazard function, $\mathrm{h}_{k}(\mathrm{t})$, or the instantaneous rate of occurrence of a particular endpoint $k$ conditional on not experiencing any endpoint until that time [38-41]. We used the hazard function to estimate the relative hazard of a collared wolf reaching an endpoint such as LTF given its survival to a particular date. We used semi-parametric Cox proportional hazard models to estimate covariate hazard ratios (HR) to model how endpoint-specific $\mathrm{h}_{k}(\mathrm{t})$ changes as a function of survival time and model covariates. The estimation of covariate effects on the endpoint-specific hazard is modeled as $h_{k}(t)=$ $h_{0 k}(t) e^{\left(\beta_{1} x_{1}+\cdots+\beta_{j} x_{j}\right)}$, where $h_{0 k}(t)$ is an unestimated baseline hazard function (i.e., semiparametric) and $\beta_{j}$ represent estimates of hazard ratios (HRs) for each covariate $x_{j}(\mathrm{HR}<1$ represents a reduction in hazard and $\mathrm{HR}>1$ an increase in hazard).

However, hazard rates do not consider competing risks. Competing risk analyses go beyond standard survival analyses by considering multiple endpoints simultaneously (e.g.: multiple causes of death, agency removal, or LTF). These models are useful for estimating the relative incidence of a particular endpoint, while accounting for other competing endpoints (e.g., the occurrence of human-caused death in the presence of a risk of natural-caused death and LTF). In a competing risk framework, individuals can potentially experience the event of interest (i.e., end of monitoring time) by multiple, mutually exclusive endpoints, although only one is observed. 
297

298

299

300

301

302

303

304

305

306

307

308

309

310

311

312

313

314

315

316

317

318

319

Because the event of interest can only occur due to one endpoint, we refer to the endpoints as 'competing' to bring about that event, and to the respective probabilities over time of that occurring as 'competing risks'.

Competing risk techniques estimate the cumulative incidence (CIF) curve for each endpoint, defined by the failure probability $\operatorname{Prob}(\mathrm{T}<\mathrm{t}, \mathrm{D}=\mathrm{k})$; that is, the cumulative probability of endpoint $k$ having occurred first (element $\mathrm{D}$ is an index variable that specifies which endpoint occurred) at time T, which specifies when the event happened within the study period interval defined over time $\mathrm{t}$ in the presence of other competing endpoints (i.e., subjects experiencing other endpoints are still considered at risk as individual wolves entered and left the risk set throughout the study period) $[37,41,42]$.

Within the competing risks framework, Fine-Gray (FG) subhazard models estimate differences in CIFs for a given endpoint conditional on covariates $[42,43]$. FG models use regression techniques similar to the Cox model, except parameter interpretation changes as follows: estimates are interpreted as subhazard ratios (SHRs) or relative incidence (rather than HRs) in the presence of other endpoints (i.e., for each covariate $x_{j}: \mathrm{SHR}<1$ represents a reduction in incidence and SHR>1 an increase in incidence). Although both hazard and competing risk models are informative, the competing risk models consider more information and provide greater predictive power $[41,42,44]$.

Hence, while endpoint-specific Cox models and their HRs allowed us to test the hypothesis that liberalized wolf-killing affected the rate of occurrence (i.e., hazard) of any endpoint relative to 
320 policy periods, the FG models and their SHRs allowed us to test if and how much liberalized

321 killing affected the probability and incidence of endpoints, in addition to the potential

322 simultaneous effects of other covariates. CIFs allowed us to visualize those effects on incidence

323 while considering the prevalence of each endpoint in the population. Therefore, we used both

324 hazard and incidence to infer the changes due to policy period and test the opposed hypotheses

325 (Table 4).

326

327 Our Cox proportional hazards and Fine-Gray subhazard models comply with the appropriate

328 number of events per variable recommended in the scientific literature to ensure accurate

329 estimation of regression coefficients and their associated quantities for the endpoints of interest

330 (poached, agency removals, LTF) (see Tables 2 and 3 below) $[34,35,45]$.

332 Following recommendations for rigorous competing risk analysis [41,42,44,46], we reported

333 results on all endpoint-specific hazards and CIFs to elucidate how hazards and incidences of

334 multiple endpoints interact. For example, analysis of Wisconsin wolves suggested the increases

335 in both the hazard and incidence of LTF during liberalized killing periods offset and potentially

336 overcompensated for the smaller decreases in hazard and incidence of reported wolf-poaching

337 estimated during those same periods [19].

339 Finally, we used Bayes' Factor (BF) [47] to assess the strength of evidence for each of our

340 alternative hypotheses and the null hypothesis for each poaching endpoint. We used the free BF

341 online calculator found at

342 http://www.lifesci.sussex.ac.uk/home/Zoltan_Dienes/inference/Bayes.htm, which assumes 
343

344

345

346

347

348

349

350

351

352

353

354

355

356

357

358

359

360

361

362

363

364

365

parameter estimates are normally distributed with known variance. The parameters used for each endpoint will be its point estimate and SE derived from the final Cox and FG models for testing HRs and SHRs, respectively. To assess the robustness of our conclusion to our prediction of the population distribution given our hypotheses and because prior theoretical support for any particular BF specification is scant, we assumed three different likelihood functions for the hypotheses' predicted effect as recommended by [47]: (1) a half-normal function using the legal removal endpoint's point estimates to model the expected standard deviation as $\mathrm{SD}=$ point estimate, (2) a uniform function using the legal removal endpoint for Mexican wolves as the upper bound and 0 as the lower bound, and (3) a half-normal using endpoint-specific estimates from [19] to calculate the SD in the same manner as (1) [47, 48]. In doing so, we follow [47]'s recommendations to use likely values while keeping our predictions blind to the data as required by a registered report. In the absence of a base of prior literature to guide us, our use of these default variances maintains the required 'blind' to our data with a reasonable estimate of variability in the distribution around the point estimate. We use the legal removal endpoint estimates (rather than other imperfectly reported endpoints) in two specifications of our hypotheses because we know there is an effect (i.e., more wolves are killed legally during legalized killing periods). We report BFs for all HRs and SHRs of interest (i.e., reported poached and LTF). BFs strength of evidence for each hypothesis (or null) was interpreted as follows: $1 / 3<\mathrm{BF}<3$, would be inconclusive evidence; $\mathrm{BF}>3$, would be substantial evidence for the alternative hypothesis; $\mathrm{BF}<1 / 3$, would be substantial evidence for the null hypothesis (i.e., no effect) $[47,48]$. Given our three BF specifications for each endpoint parameter, we would conclude in favor of a particular hypothesis if most BF specifications (2 out of $3 \mathrm{BFs}$ ) support that conclusion. Accordingly, we might generate contradictory evidence (strong support for each 
hypothesis and the null) or inconclusive evidence (failure of any hypothesis to survive a majority

367 of the BF specifications). For purposes of comparison, and to provide estimates of policy effects

368 on 'total potential' (cryptic + reported) poached, we also aggregate and run all analysis on the

369 new endpoint LTF+POA (including the procedure for pre-specified BFs as above).

371 Diagnostic Step

372 Because we used information from two data sources (MWRP and OLE datasets), we analyzed

373 the data in two steps to provide more nuance about the effect of the policy intervention on

374 mortality and disappearance. Both steps employed all survival and competing risk analyses

375 previously described. We analyzed four endpoints: 'human, 'natural', 'LTF', and 'agency

376 removal' (Table 2). The drawback from this endpoint breakdown is the inability to conclude

377 anything directly regarding any policy effects on subsets of anthropogenic mortality (e.g.,

378 poaching or non-criminal human-caused deaths).

Analyses

381 We added OLE data on human-caused endpoints and further specified which were poaching and

382 which were deemed non-criminal (Table 3). However, this comes at the expense of lower

383 number of observations in each human-caused endpoint and reduced statistical power (fewer

384 events per variable, see previous section and Tables 2 and 3). Thus, results from the diagnostic

385 step above will prove more statistically robust, but the exploration of the various anthropogenic endpoints is imperative, given evidence of different policy effects on each [19]. 
By evaluating the effect(s) of both liberalized killing periods (SOP 13 and revised 10(j) Rule), we will strengthen the inference about the policy intervention with a better case-control design (reverse-treatment or before-during-after-during). Therefore, both policy periods will be sampled twice.

Two divisions of the USFWS did the preliminary quality check on data. First the Mexican Wolf Recovery team collected mortality and disappearance data with a simple endpoint classification as 'died of natural cause, died of human cause, legal removal by agency, disappeared (LTF).' Next, for the subset of human-caused deaths above, the independent USFWS OLE classified deaths by cause (vehicle, poaching, accidental) and occasionally reclassified a human-caused death as natural after detailed investigations, some or all of which included necropsy, radiography, or field investigation. Within our team, the two co-lead authors performed interobserver reliability tests by independently taking the data provided by the USFWS and summarizing it (Tables 2 and 3), then comparing and resolving discrepancies (arbitrated by the senior author in case of disagreements).

In Phase 2, the two co-lead authors separately prepared the data for analysis by aligning individual wolf survival histories with covariates and the intervention (policy period). The senior author Dr. Treves is Dr. Santiago-Ávila's post-doc supervisor and Ms. Louchouarn's PhD advisor. He and David R. Parsons served as a skeptical trouble-shooter for analyses, interpretation, and writing - blind to results until the Phase 2 analysis was considered complete by the two co-lead authors. This team organization and separation of powers was intended to reduce bias and improve the strength of inference. 
412 Table 2. Number of endpoints (unique wolf IDs) during periods of liberalized killing or periods

413 of stricter protections for step 1 (diagnostic step). Wolves that survived to the end of the study

414 period $(n=52)$ are omitted here and censored in analyses. The study period spanned March 29,

4151998 to December 31, 2016 inclusive.

\begin{tabular}{|l|l|l|}
\hline Endpoint & Stricter & Liberalized \\
& protection, policy & killing policy \\
& $(\mathrm{t}=4,621$ days $)$ & $2,230$ days $)$ \\
\hline Agency Removal & 28 & 20 \\
\hline Natural cause & 11 & \\
\hline Human cause & 55 & 11 \\
\hline LTF & & 35 \\
& & \\
\hline & & \\
\hline
\end{tabular}


418 Table 3. Number of endpoints (unique wolf IDs) during periods of liberalized killing or periods

419 of stricter protections for step 2 using OLE data from investigations of suspicious deaths. Wolves

420 that survived to the end of the study period $(n=52)$ are omitted here and censored in analyses.

421 The study period spanned March 29, 1998 to December 31, 2016 inclusive.

\begin{tabular}{|l|l|l|}
\hline Endpoint & Stricter & Liberalized \\
& protection, policy & killing policy \\
& $(\mathrm{t}=4,621$ days $)$ & $2,230$ days $)$ \\
\hline Agency Removal & 28 & 20 \\
\hline Poaching & 35 & \\
\hline Natural Death & 11 & 17 \\
\hline LTF & & \\
\hline & & \\
\hline
\end{tabular}


Table 4. Relationship between our hypotheses, proposed analyses and interpretation of outcomes (including contingent interpretation

LTF endpoint.

\begin{tabular}{|c|c|c|c|c|}
\hline Question & Hypotheses & $\begin{array}{l}\text { Sampling plan (e.g. } \\
\text { power analysis) }\end{array}$ & Analysis Plan & $\begin{array}{l}\text { Interpretation given different } \\
\text { outcomes (note see footnote } \\
\text { and main text for Bayes factor } \\
\text { specifications } \dagger \text { ) }\end{array}$ \\
\hline $\begin{array}{l}\text { Do hazard rates or } \\
\text { cumulative incidence of } \\
\text { death by poaching or } \\
\text { disappearance (DV) of } \\
\text { wild, collared adult } \\
\text { Mexican grey wolves } \\
\text { change after policies } \\
\text { change (IV) from strict } \\
\text { protection to liberalized } \\
\text { killing and back again. }\end{array}$ & $\begin{array}{l}\text { 'Killing for tolerance' } \\
\text { predicts the hazard and } \\
\text { incidence decline for } \\
\text { the endpoint 'poached' } \\
\text { (poa) or the endpoint } \\
\text { LTF when the IV of } \\
\text { policy period } \\
\text { liberalizes wolf- } \\
\text { killing. }\end{array}$ & $\begin{array}{l}\text { All collared wild } \\
\text { Mexican gray wolves } \\
\text { from MWRP and OLE } \\
\text { 1998-2016 (n=279) } \\
\text { A diagnostic test is run } \\
\text { on the samples with } \\
\text { four endpoints } \\
\text { (human, natural, } \\
\text { removal, LTF) before } \\
\text { proceeding to the } \\
\text { analysis plan (See } \\
\text { Diagnostic Step). } \\
\text { See Tables } 2 \text { and } 3 \text { for } \\
\text { endpoint-specific } \\
\text { sample sizes split by } \\
\text { the IV of policy } \\
\text { period. }\end{array}$ & $\begin{array}{l}\text { For MWRP and OLE } \\
\text { datasets: } \\
\text { Endpoint-specific Cox } \\
\text { multiple regression } \\
\text { models (for each } \\
\text { endpoint) on the IV of } \\
\text { policy period and } \\
\text { other covariates. } \\
\text { Competing risk Fine \& } \\
\text { Gray multiple } \\
\text { regression models (for } \\
\text { each endpoint) on the } \\
\text { IV of policy period } \\
\text { and other covariates. } \\
\text { CIFs allow for } \\
\text { analysis of population } \\
\text { effects (incidence) } \\
\text { while considering the } \\
\text { prevalence of each } \\
\text { endpoint in the } \\
\text { population. }\end{array}$ & $\begin{array}{l}\mathrm{HR}_{\mathrm{poa}} \text { and } \mathrm{HR}_{\mathrm{ltf}} \text { are }<1 \\
\quad \mathrm{OR} \\
\left(\mathrm{HR}_{\text {poa }} \text { has to be }<1 \text { and }\right. \\
\text { greater in magnitude than any } \\
\text { increase in } \mathrm{HR}_{\mathrm{ltf}} \\
\quad \mathrm{OR} \\
\mathrm{HR}_{\mathrm{ltf}} \text { has to be }<1 \text { and greater } \\
\text { in magnitude than any } \\
\left.\text { increase in } \mathrm{HR}_{\text {poa }}\right) \\
\quad \text { AND } \\
\text { endpoint-specific CIFs } \\
\text { estimate which endpoint has a } \\
\text { greater effect on the } \\
\text { population (from Fine-Gray } \\
\text { models of competing risks) } \\
\text { The criterion for determining } \\
\text { if 'TOTAL potential poached' } \\
\text { probability f declined is a } \\
\text { decline in the combined } \\
\text { incidence of LTF and POA. }\end{array}$ \\
\hline
\end{tabular}




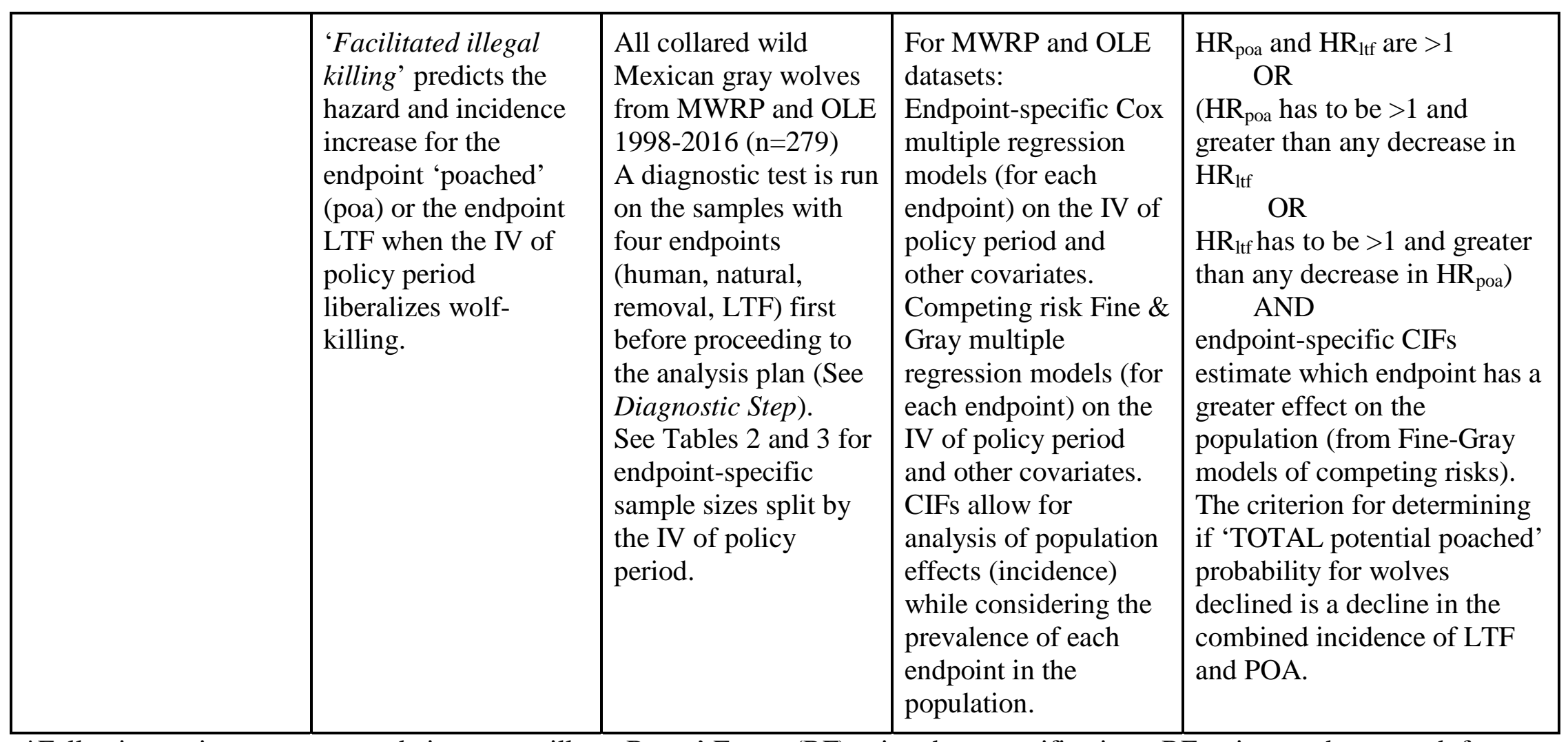

431 Methods section above). 


\section{Timeline}

434 We are able to start work immediately following acceptance. Our anticipated timeline for

435 completion pending acceptance of our submission is the following: 4-5 weeks to conduct all

436 statistical analyses and 3-4 weeks for writing and submission. 


\section{Results}

438 The two policy periods we examined which liberalized killing of Mexican wolves resulted in

439 various changes in the hazard and incidence of endpoints of collared wolves relative to the two

440 periods of stricter protection. The diagnostic step (SM1) and results that follow confirmed the

441 importance of disaggregating human-caused endpoints to assess the evidence for our alternative

442 hypotheses.

443 Covariates of winter and sex did not significantly affect the results of any models, and therefore

444 the most parsimonious model included the policy intervention without either covariate. The

445 proportional hazard assumption of Cox models was met for all endpoints (see Suppl. Fig. S7-S8).

446 For information about each model and their parameters, see supplemental materials (Suppl.

447 Table S1). The best models revealed the following changes for collared Mexican wolves:

448 Lost to follow-up (LTF). Periods of liberalized killing were associated with a $121 \%$ increase in

449 the hazard for the endpoint of LTF, relative to periods of stricter protection, compatible with a

450 positive range (does not include zero) of $+36 \%$ to $+260 \%(\mathrm{HR}=2.21, \mathrm{p}<0.001$; Table 5, Fig. 1-

451 B). The proportion of collared wolves (CIF) with the endpoint of LTF increased by $128 \%$ (SHR

$452=2.28$, compatible interval $=38-276 \%, \mathrm{p}<0.001)$ during periods of liberalized killing relative to

453 periods of stricter protection (Table 6, Fig 1-A).

454 Reported poached. Periods of liberalized killing were associated with a $22 \%$ decrease in hazard

455 for the endpoint of reported poached, relative to periods of stricter protection, compatible with a

456 range that overlaps zero of $-56 \%$ to $+39 \%(\mathrm{p}=0.407$; Table 5, Fig. 1-D). The proportion of

457 collared wolves (CIF) with the endpoint of reported poached decreased by $31 \%$ (SHR=0.69, 
458

459

460

461

462

463

464

465

466

467

468

469

470

471

472

473

474

475

476

477

478

479

compatible interval $=-62 \%$ to $+25 \%, \mathrm{p}=0.226$ ) during periods of liberalized killing relative to periods of stricter protection (Table 6, Fig. 1-A).

Agency Removal. Periods of liberalized killing were associated with a 5\% increase in hazard for the endpoint of agency removal, relative to periods of stricter protection $(\mathrm{HR}=1.05$, compatible interval includes zero, $-41 \%$ to $+88 \%, \mathrm{p}=0.863$, Table 5 , Fig 1-C). The proportion of collared wolves (CIF) with endpoint of agency removal decreased by $4 \%$ (SHR $=0.959$, compatible interval includes zero, $-48 \%$ to $+75 \%, \mathrm{p}=0.892$ ) during periods of liberalized killing relative to periods of stricter protection (Table 6, Fig 1-A).

Non-criminal. Periods of liberalized killing were associated with a $42 \%$ increase in hazard for the endpoint of non-criminal causes, relative to periods of stricter protection $(H R=1.42$, compatible interval includes zero, $-25 \%$ to $+171 \%, \mathrm{p}=0.278$, Table 5$)$. The proportion of collared wolves (CIF) with the endpoint of non-criminal increased by $27 \%$ (SHR=1.27, compatible interval includes zero, $-33.7 \%$ to $+146 \%, \mathrm{p}=0.463$ ) during periods of liberalized killing relative to periods of stricter protection (Table 6).

Natural. Periods of liberalized killing were associated with a $28 \%$ increase in hazard for the endpoint of natural causes relative to periods of stricter wolf protections ( $\mathrm{HR}=1.28$, compatible interval includes zero, $-47 \%$ to $+208 \%, \mathrm{p}=0.582$, Table 5 ). The proportion of collared wolves (CIF) with the endpoint of natural increased by $32 \%$, compatible interval $=-44 \%$ to $+211 \%$ $(\mathrm{SHR}=1.32, \mathrm{p}=0.526 ;$ Table 6$)$.

Total potential poached. Periods of liberalized killing were associated with a $42 \%$ increase in hazard for the endpoint of total potential poached (aggregated endpoint of LTF and reported poached), relative to periods of stricter protections $(H R=1.42$, compatible interval $=-0.7 \%$ to 
$480+103 \%, \mathrm{p}=0.05)$. The proportion of collared wolves (CIF) with endpoint of total potential

481 poached increased by $38 \%(\mathrm{SHR}=1.38$, compatible interval $=-5 \%$ to $+101 \%, \mathrm{p}=0.095)$.

482 Bayes factors. We calculated Bayes Factors (BF) with three specifications to model the expected 483 predicted and maximum effect (Suppl. Table S2). BFs were inconclusive $(1<\mathrm{BF}<3)$ for most

484 endpoints, suggesting the data are inconclusive for distinguishing the hypotheses from the null,

485 following recommended criteria for BF interpretation (Table 4). Indeed, all three BF

486 specifications proved inconclusive for the reported poached and total potential poached

487 endpoints, which does not support the tolerance killing hypothesis. However, our presumption

488 that agency removal increased during periods of liberalized wolf-killing was not supported (HR

$489=1.05$ and SHR=0.96), therefore specifications 1 and 2 seem meaningless (Table 7). By contrast,

490 the third specification of BF, based on endpoint-specific estimates of predicted effect as

491 recommended by Dienes [47,48] were meaningful (Table 7). These are conclusive evidence of

492 an increase in LTF during liberalized wolf-killing periods $(\mathrm{BF}=8.08)$; that specification was

493 inconclusive on changes for reported and total potential poached endpoints. See supplemental

494 materials for information about the inputs used to calculate BFs (Suppl. Table S2).

495

496 Discussion

497

498 Here we report a replication of the findings of Santiago-Ávila et al. [19] that grey wolves that

499 disappeared from monitoring did so at higher rates during periods of reduced protections (i.e.,

500 liberalized killing) than during periods of stricter protections under the U.S. Endangered Species

501 Act (ESA). We find stronger evidence for this pattern among collared Mexican wolves (C. $l$.

502 baileyi) than was found among collared grey wolves in Wisconsin, USA [19]. Because the 
disappearance of collared wolves that are being monitored by VHF or GPS is most often caused by illegal activities $[5,7,49]$, the present study further undermines the common assumption that animals lost to monitoring suffer from the same hazards and endpoints as those animals that are perfectly monitored [4].

In the paragraphs below, we first justify the assertion that the observed pattern in disappearances results from increases in cryptic poaching. Second, we conclude that our results support the "facilitated illegal killing" hypothesis and do not support the "killing for tolerance" hypothesis. Third, we discuss strength of inference in this subfield of wildlife science including protections against bias used in this study for the first time in this subfield to strengthen inference. Fourth, we propose that legal killing, non-lethal removal from the wild, and facilitation of cryptic poaching are all impediments to endangered wolf recovery under the Endangered Species Act (ESA). Finally, we discuss the general lessons we draw from this study for the U.S. federal agency implementing the ESA (USFWS) for wolves generally, for other countries, and for antipoaching research and intervention.

The relative stability in hazard and incidence of all known fates (not including the subset of radio-collared Mexican wolves that were designated LTF, lost to follow-up) between policy periods would suggest that if LTF wolves were in fact lost due to the same endpoints as monitored individuals with known fates, then we should observe relative stability in hazard and incidence of LTF between policy periods. This is not the case in either this study or [19]. Past work provides numerous independent lines of evidence that the majority of LTF could not be emigrants nor transmitter failures. First and most importantly, in both this study and that of 
526 Santiago-Ávila et al. [19], hazard and incidence rates of LTF changed in correlation with policies

527 on legal killing, which could not plausibly have caused transmitter failures; see also [49] on

528 different rates of LTF between hunting and non-hunting seasons. Also, battery life might be

529 confounding LTF occurred long after collaring. Contrary to this expectation, LTF was much

530 shorter (average 788 days) than the average length of time to the natural mortality endpoint

531 (1175 days). If battery life were the confounding factor, we would expect average time to LTF to

532 be more similar to average time to the natural mortality endpoint. Second, if LTF were largely

533 made up of emigrants from the Mexican wolf recovery area, some of these individuals would

534 likely have been found dead in surrounding areas by citizens with nothing to hide who

535 presumably would have reported their observations to authorities. The USFWS databases we

536 used contained no such cases. Therefore, LTF wolves were most likely killed and the evidence of

537 the illegal action was concealed, e.g., by destruction of transmitters. Such cryptic poaching was

538 first estimated by Liberg et al [7], and subsequently explored in Treves et al [4,5] and Santiago-

539 Ávila et al. [19], and could have been exacerbated in the Mexican wolf recovery area by the

540 policy of sharing radiofrequencies of collared wolves with members of the public [50]. We

541 conclude that our results on the disappearances of collared Mexican wolves reinforce those first

542 reported by Treves et al. [5] which demonstrated the bias introduced by excluding

543 disappearances of marked wolves in mortality analyses for four endangered wolf populations.

545 We tested opposed hypotheses about the effect of legalizing killing or removal of individuals of

546 an endangered species on the survival of collared individuals remaining in the wild. The

547 USFWS, responsible for implementing the ESA for terrestrial species, has been a particular

548 supporter of the 'killing for tolerance' hypothesis. It has repeatedly invoked this hypothesis in its 
549

550

551

552

553

554

555

556

557

558

559

560

561

562

563

564

565

566

567

568

569

570

571 endangered grey wolf management under the assumption that government-permitted killing of grey wolves would mitigate or prevent illegal killing and raise public tolerance for wolves, so ongoing recoveries would not be stopped or slowed by illicit resistance [9,51]. A federal court rejected that argument as a speculative approach to abridging the ESA prohibitions that are explicitly aimed at preventing killing [9] but in 2017 another court seemed to defer to the agency on this point when it wrote "... it is clear that in drafting the present Section $10(\mathrm{j})$ rule, the take provisions are critical to conciliating those opposed to the reintroduction effort,.." p.43 [9].

Despite this deference, the court remanded the rule to the USFWS to repair its deficiencies. We recommend the USFWS abandon the expectation and repudiate the oft-repeated and unsupported notion that liberalizing killing would reconcile opponents of wolf protection. The results of this study support the alternative and mutually exclusive hypothesis that liberalized killing policies facilitate illegal killing and join a growing body of evidence that suggests liberalized killing policies lower tolerance for wolves and slow wolf population growth substantially more than expected from legal killing rates.

This study therefore adds to literature regarding policy effects on anthropogenic causes of wolf mortality. Human dimensions research using focus groups and mail-back surveys measuring attitudes of Wisconsin residents in and out of wolf range found that respondents' tolerance for wolves decreased and reported respondents' willingness to poach wolves increased after wolfkilling was liberalized seven times between 2003 and 2013 [12,14]. Moreover, calls for more killing of wolves followed relaxing ESA protections [13]. Further, a study of population dynamics showed with $92 \%$ certainty that there had been an unexplained decrease in the growth of wolf populations in both Wisconsin and Michigan after wolf killing was liberalized, 
572 independent of the number of wolves killed legally $[15,16]$. The latter authors could only explain

573 the repeated, parallel slow-downs by the existence of undetected mortality [15,16], a result which

574 withstood a series of attempts at rebuttal that did not include new data [17] and in one case

575 muddied the waters with errors and omissions [23]. The conclusion from Chapron \& Treves

$576[15,16]$ that the length of the policy period was predictive of the population growth slow-down

577 independent of the reported number of wolves killed is consistent with our finding that exposing

578 Mexican wolves to liberalized killing was associated with higher hazard and incidence of LTF,

579 not predicted by the hazard or incidence of wolves legally killed. Therefore, three independent

580 lines of evidence point in the same direction and opposite to the USFWS hypothesis about

581 liberalizing killing.

582

583 Moreover, here we provide more direct, stronger inference than ever before, against the

584 government's 'killing for tolerance' hypothesis in a new population of wolves. Given that periods

585 of reduced protections allowed for greater flexibility in legal lethal actions towards Mexican

586 wolves, we expected to observe a higher increase in hazard of agency removals during periods of

587 reduced protections $(\mathrm{HR}=1.05)$. Therefore, we reject the possible explanation that increased

588 hazard or incidence of agency removal $(\mathrm{SHR}=0.95)$ during liberalized killing periods is

589 somehow leading to an increase in disappearances (such as emigration or super-additive

590 mortality). Rather, it was the policy period announcement or its duration per se that had the

591 effect of increasing collared wolf disappearances. Chapron \& Treves [15] proposed that reducing

592 protections for wolves sends a policy signal lowering the value of wolves to the public including

593 would-be poachers or reducing the likelihood of enforcement against poaching. The

594 hypothesized 'policy signal' seems to convey that either the lives of individual wolves are 
595 perceived as less valuable, the benefit of wolves has declined, or prosecution of poachers will

596 relax. We find little evidence to support the latter, because the LTF endpoint represents

597 destruction of evidence of poaching. Instead, would-be poachers appeared to have opted to act

598 cryptically or increase their concealment of evidence during periods of reduced protection, an

599 inference that is supported by a recent news report [52]. The inference that would-be poachers

600 became more concerned with law enforcement while increasing their poaching rates is consistent

601 with the current study in Mexican wolf range and that of Santiago-Ávila et al. [19] for Wisconsin

602 wolves.

603 Until sophisticated, replicable studies of confirmed poachers and their attitudes are conducted,

604 we cannot know if would-be poachers responded to policy signals by repeating past poaching

605 behavior with the addition of more concealment of evidence, or if new actors began poaching

606 with concealment. We predict a mix of both patterns, but a preponderance of the poaching during

607 periods of liberalized killing was by individuals who now chose to conceal evidence. That

608 pattern would be supported if the USFWS began to give out radiofrequencies of collared wolves

609 or otherwise changed agency conduct in the field in such a way as to expose collared wolves to

610 higher risk.

612 In past studies, including those from the U.S. Midwest, as well as one performed in Scandinavia

613 [8], periods of reduced wolf protection were associated with significant increases in hunting or

614 government lethal removal of wolves. Rates of wolf disappearances or poached wolves also

615 increased, but not as drastically as we observe here. These less drastic changes for other

616 endpoints may be a result of 'cleaning up the numbers' $[8,19]$; more wolves reach the endpoint

617 of legal killing before they can succumb to some other endpoint, such as reported or cryptic 
618

619

620

621

622

623

624

625

626

627

628

629

630

631

632

633

634

635

636

637

638

639

640

poaching, thereby muddying our understanding of the effect of legal killing policies on other fates of collared wolves. Our study is not confounded by any effect of 'cleaning up the numbers' because Mexican wolves were not subject to higher hazard of legal removal and the incidence of wolves lost by agency removal decreased, yet radio-collared wolves disappeared at higher rates. Rather, we detected significantly more hazardous conditions for the critically endangered Mexican wolf when the USFWS reduced ESA protections independent of agency removal.

Regarding the unexpected finding that the rate of agency removal changed little as policy periods changed from stricter protection to reduced protection, we re-examined our starting assumption. We based our starting assumption of a higher increase in agency removals during two periods of reduced protection (SOP13 and revised 10j rule) on two pieces of likely misleading information. First, by examining the raw numbers of agency removals in Tables 2 and 3, it appears that the prevalence of wolves being removed during periods of liberalized killing is about $150 \%$ of that being removed during periods of stricter protections. However, hazard and incidence, as we calculate here with survival analysis methods, are based off the sum of all the days each wolf was exposed to each endpoint (i.e., their aggregate time-at-risk). Therefore, time-at-risk is much greater than number of days over particular policy periods (as reported in Tables 2 and 3). We further based our expectations of the change in agency removals over policy periods on a source which claimed that agency removals more than doubled during the SOP-13 policy relative to prior years (see Methods section) [31]. However, [31] lacks any accompanying data.

An often-overlooked aspect of wolf mortality reporting is how the agency classifies cause of death when human-caused. Treves et al. [4] mentioned consolidating causes of death such as non-permitted trapping, shooting, poisoning into one category of poaching, especially when the agency might otherwise misidentify the primary cause of death. We observed a pattern in the 
641 data for Mexican wolves that was not detected in Santiago-Ávila et al. [19]. In particular, the

642 incidence of the non-criminal endpoint increased by $27 \%$ during periods of reduced wolf

643 protections (Table 6). Our results $(\mathrm{HR}=1.42$ and $\mathrm{SHR}=1.27)$ for the non-criminal endpoint

644 suggest the possibility that USFWS staff classified a greater number of anthropogenic causes of

645 death as non-criminal during periods of reduced protections. This may be a logical result of

646 liberalizing killing, as less killing is legally classified as 'poaching'. Indeed, some poaching could

647 merely have been reclassified as non-criminal by USFWS staff using subjective definitions and

648 thereby confirming the (erroneous) perception that poaching had diminished because of

649 'increased tolerance.' However, the non-criminal endpoint includes vehicle collisions, and other

650 human-caused mortalities that were classified as non-criminal after an investigation by the

651 USFWS Office of Law Enforcement (OLE). Therefore, it is impossible to know the real cause of

652 the increase in hazard and incidence of the non-criminal endpoint during periods of reduced

653 protections without knowing more about the OLE investigations. We received two datasets for

654 Mexican wolves from the USFWS. One set pooled all anthropogenic mortality in one category,

655 which is clearly less useful for analyses such as ours that can tease apart the effect of policy

656 interventions on specific endpoints. Hence, the second dataset from OLE which assigned

657 criminal and non-criminal causes of death and also distinguished further subcategories was much

658 more useful to us. We surmise it would have been more useful to managers and the public also.

659 Therefore, we recommend the USFWS share data on mortality of endangered species that are

660 disaggregated into no fewer than four categories (legal, illegal, vehicle collision, and natural),

661 report disappearances (LTF) systematically in the same tables along with start and end dates for

662 time on the air. By the same token, too many categories of poaching as a cause of death can

663 obscure the priority of illegal killing. 
664 Some readers might wonder if frustration among would-be poachers rose in the Mexican wolf

665 range because agency removals did not change between periods, despite the policy signal that

666 protections were loosened. However, we argue that if this were a valid explanation, we would

667 expect frustration with the lack of change in rate of lethal actions to be prevalent during both

668 policy periods, and we would anticipate the rate of disappearance of wolves to be comparable

669 during the two periods, which we do not see. We would therefore expect a different pattern than

670 in the U.S. Midwest where the agency did use liberalized killing periods to lethally remove

671 wolves at higher and increasing rates [19]. Proponents of the frustration hypothesis claimed

672 Wisconsin's would-be poachers were frustrated when protections were tightened [11]. No

673 plausible cognitive mechanism that would differ between would-be poachers of Wisconsin and

674 those of New Mexico/Arizona has been presented. The frustration hypothesis requires two

675 different cognitive behavioral mechanisms exist in the two populations, which does not seem

676 parsimonious and is not consistent with the attitudinal data from Wisconsin (see above). This

677 Mexican wolf study cannot support the USFWS idea that without legal recourse, actors would

678 take matters into their own hands because would-be poachers observing agency removals would

679 be expected to be as frustrated in and out of the policy periods examined here.

680 Because this study and Santiago-Ávila et al. [19] used time series analysis for before-and-after comparison of interventions (BACI) without randomization to control or treatment, it provided stronger inference than prior work that relied on correlation and single point estimates

$683[11,15,16]$, by accepted standards from other fields [53,54]. The standards have been explained 684 at length in [55-57] in relation to their application to evaluation of methods to prevent carnivore 685 attacks on livestock. The current study also integrated several novel protections against bias that 
687

688

689

690

691

692

693

694

695

696

697

698

699

700

701

702

703

704

705

706

707

708

709

that just over half of the wild Mexican wolves were marked and monitored, compared to the average of $13 \%$ marked in the Wisconsin population. That increases the strength of generalizations about Mexican wolves as a whole and increases our confidence in parameter estimates for known and unknown fates in the present study. Therefore, only evidence using experimental controls could achieve stronger inference than does the current study.

Furthermore, this study directly attempted to reduce bias in the following ways. First, we used official data as classified by the management agencies in charge (both USFWS MWRP and its OLE), not by us. Therefore, if any bias exists in the classification scheme, it reflects classification decisions by the agencies and probably random error given the agencies were apparently unaware of the hypotheses. Second, by publishing methods before completing an analysis, we ensured that the analyses could not be amended to support one or another hypothesis. Further, peer-review of the methods helped our team develop stronger analysis methods that would allow us to better interpret the strength of the evidence. Fourth, we used Bayes Factors rather than arbitrary traditional significance thresholds to assess relative strength of evidence for our hypotheses. Our team also developed internal safeguards by having separate members of the team independently interpret the results without taking part in analysis. The ESA requires the use of best available scientific and commercial data, hence policymakers wishing to implement the ESA as intended by Congress can take comfort that the science has advanced to the highest level, rather than continuing to debate with imperfect evidence as the scientific community did from 2013-2019 (reviewed above in the section on hypothesis tests).

We conducted a Bayes Factor (BF) analysis to quantitatively assess the strength of evidence for our two competing hypotheses and the null hypothesis. Calculating BFs for each endpoint allows us to go beyond significant or non-significant results to examine whether non-statistically 
710

711

712

713

714

715

716

717

718

719

720

721

722

723

724

725

726

727

728

729

730

731

significant results truly represented evidence against either hypothesis [47]. To determine whether our results represent evidence for or against either opposing hypothesis or the null hypothesis, Dienes [47] recommends using prior published research to determine what our theory predicts. The theories we test here have not been widely tested, therefore our best source for endpoint-specific parameter estimates came from Santiago-Ávila et al. [19].

Those prior results from an unrelated dataset provided a comparison for the Mexican wolf results in a registered report but prior to analyzing the data. We calculated the BFs of our results using three specifications (defined in Methods) and, following our stated interpretation criteria for BFs detailed in the Methods and Table 4, none of our endpoints of interest (LTF, poached, total poached) provided conclusive evidence for either of our alternative hypothesis (Suppl. Table S2). However, we have greater confidence in the results calculated using the third specification; the half normal distribution calculated using prior data; Santiago-Avila et al [19]'s HR and SHR values for the LTF and 'reported poached' endpoint. Our rationale for our confidence in the third specification is as follows: (a) the effects observed in both studies are endpoint specific, therefore the estimates used ([19]s HR and SHR) are a result of similar mechanisms, rather than using estimates from different endpoints that likely result from different mechanisms, as in our other two specifications, both based on using the Mexican wolf agency removal endpoint for comparison; (b) when submitting our methods as a registered report, we had to make a 'blind' (prior to analyses) assumption regarding the change in agency removal endpoint for Mexican wolves (i.e., that agency removals would increase with liberalized protections), which proved counter-intuitively unchanged between policy periods, thereby eliminating its potential

predictive power; (c) the agency removal and reported poached HRs are opposite in direction and 
732 the same occurs with the agency removal and LTF SHRs, so those estimates do not provide

733 plausible parameters for the reported poached and LTF endpoints.

734 The only BF that was conclusive was the support for the 'facilitated illegal killing' hypothesis

735 shown by the increase in disappearances of collared Mexican wolves (LTF, Table 7). This BF

736 value fell below the criterion level when we combined reported poached with LTF for our total

737 potential poached endpoint because the aggregated endpoints ran in opposite directions, but the

738 increase in proportion of wolves with fate LTF was nearly 3 times greater than the decrease in

739 the proportion of wolves reported poached. None of the BF analyses supported the tolerance

740 killing hypothesis (Table 7). We conclude the USFWS claim in federal court that lessening ESA

741 protections with the 10(j) rule would reconcile opponents of reintroduction and in turn be

742 harmless for the Mexican wolves in the wild [58] now seems untenable.

\section{Implications for Endangered Species}

744 Policy interventions should be effective, i.e., achieve their goals, without serious, unwanted side-

745 effects. This study finds that for Mexican wolves, there were serious side-effects of the

746 liberalized killing policies. The increase in disappearances of Mexican wolves we detected was

747 substantial during those periods of reduced protections, despite a lack of change in the rate of

748 government removal of wolves. Unplanned, unregulated disappearances are wasteful: a waste of

749 taxpayer money spent on telemetry and relocation to the wild; a loss of individual animals that

750 are unique and irretrievable by known technology; a waste of private resources used in their

751 captive breeding; and undermines the role of the federal government as trustee of U.S. wildlife

752 since 1842 [3]. The effect we found also demonstrates widespread unlawful disregard for the

753 most popular environmental law ever passed in the USA [59]. 
754 Further, the policy of liberalizing killing cannot be justified by the vague and indirect claim that

755 it speeds population growth at the expense of individual survival because USFWS data show that

756 the Mexican wolf population declined from 55 to 42 during a 6-year period of liberalized killing

757 from 2004 to 2009 [50]. Similarly, after the implementation of the $10 \mathrm{j}$ revised rule in 2015, the

758 Mexican wolf population in the wild declined $12 \%$, partially rebounded the next year, and did

759 not change by 2017 when the court order remanded the revised $10 \mathrm{j}$ rule to the USFWS.

760 Thereafter, growth continued at the prior rate averaging $22 \%$ per year [Figure 5, 50]. The latter

761 finding replicates that of Chapron \& Treves. [15-17,23] for Wisconsin's and Michigan's grey

762 wolves. Currently the Mexican wolf population numbers 163 [60]. In view of these results, we

763 hypothesize that pop growth will slow, halt and maybe even reverse given currently authorized

764 liberalized killing, with the effect on growth mediated by the magnitude of the policy signal on

765 disappearances; that is, on cryptic poaching rather than agency removals. However, protections

766 for Mexican grey wolves could be strengthened in a revised 10j rule being considered by

767 USFWS.

768 In this context, the balance tilts toward the Mexican wolves by law (quoting the court in Center

769 for Biological Diversity v Jewell (2018) "Harm to endangered or threatened species is

770 considered irreparable harm, and the balance of hardships will generally tip in favor of the

771 species. See Marbled Murrelet v. Babbitt, 83 F.3d 1068, 1073 (9th Cir. 1996) ('Congress has

772 determined that under the ESA the balance of hardships always tips sharply in favor of

773 endangered or threatened species.'); Amoco Prod. Co. v. Vill. of Gambell, AK, 480 U.S. 531, 545

774 (1987) ('Environmental injury, by its nature, can seldom be adequately remedied by money

775 damages and is often permanent or at least of long duration, i.e., irreparable. If such injury is

776 sufficiently likely, therefore, the balance of harms will usually favor the issuance of an injunction 
777

778

779

780

781

782

783

784

785

786

787

788

789

790

791

792

793

794

795

796

797 conservation interventions. Arizona, 2018). Department of Interior [62].

to protect the environment.')” p. 23, Docket CV-15-00019-TUC-JGZ, U.S. District Court

The issue goes beyond Mexican wolves. As recently as 14 December 2020, the USFWS continued to espouse the unsupported view that reducing or removing ESA protections will help individual wolves to survive and help wolf populations to recover [51]. In the latter letter to the State of California Fish \& Wildlife Commission, the USFWS cited outdated studies that have been superseded since 2016, with frequent communications directly to the USFWS in Atkins [61] and a memo to the White House Office of Management and Budget with 5 staff from the

There are lessons in the current work that have implications beyond the USA and beyond wolves. We suggest other national policies for killing large predators (or other non-humans) to raise tolerance or lower poaching should be scrutinized for strength of inference and the quality of evidence (e.g., Liberg et al. [21]; Treves et al. [22]). The notion that protection for large carnivores generates poaching as a form of rural resistance has merit, but the suggestion that relaxing protections is the solution is no longer credible (contra Kalternborn \& Brainerd [63]).

Similarly, the long-held notion that without compensation for losses, affected people will kill wildlife illegally, needs re-examination in the light of our current results. The alternative is that compensation might encourage hostage-taking, i.e., an escalation by affected parties to threatening endangered species if they are not better compensated for property damages. Our findings join an active debate about leniency versus enforcement as more functionally effective 
799 In cases of wildlife trade, such as ivory or rhino horn, arguments for leniency are focused around

800 creating a legal trade to inhibit the lucrative illegal trade $[64,65]$. However, sources of wildlife

801 crime stemming from conflict, such as in the case of grey wolves, may not be effectively

802 understood, nor managed in the same ways. Leniency has been tried for grey wolves, and

803 evidence suggests leniency fails to achieve greater tolerance and reduced wildlife crime. On the

804 contrary, leniency is associated with increased poaching of wolves in the US. We encourage the scientific evaluation of all candidate interventions as experiments, preferably with suitable comparisons or even experimental controls, with safeguards against bias.

We suspect wolves are not exceptional among large carnivores regarding the effect of relaxing or and lions have been used whenever prohibitions on hunting or other lethal management are

811 proposed [10,66-68]. We urge that similar studies be completed to examine whether there is in

812 fact a difference in how liberalized killing policies affect other large carnivores. Further, we

813 hypothesize that it is the attitudes and values of the human actors that are the unifying variable,

814 not the nature of the environmental component or species of wildlife. Our interpretation of these

815 findings, given their consistency with past studies, is that when policies are implemented which

816 reduce the value of non-human beings, such as policies which enable their killing for the sole

817 benefit of human actors, there will be increased harm to those beings and damage to the

818 environment, including crimes. 


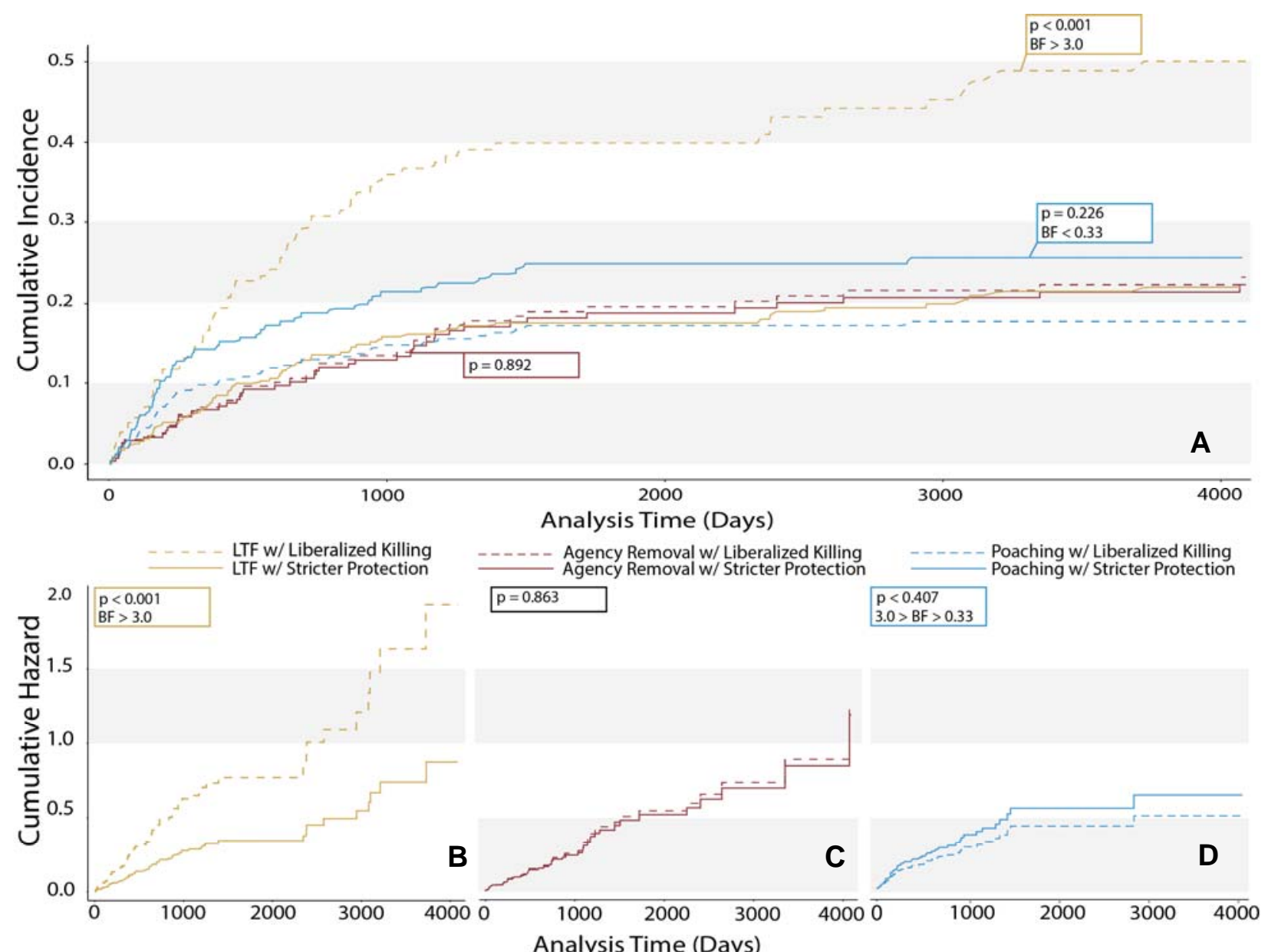

Figure 1. Cumulative incidence functions (CIF, panel A) derived from Fine-Grey subhazard models and hazard functions derived from univariate Cox models (panels B-D) for 279 collared

823 Mexican wolves during periods with reduced protections for wolves (liberalized killing periods $=$

824 1, dashed lines) and periods with stricter protections (solid lines) for three independent endpoints

825 (LTF, $n=67$; reported poached, $n=52$; and agency removal, $n=48$ ). See Supplemental Materials

826 for the cause-specific hazard functions (Suppl. Fig S1-S2) and CIFs (Suppl. Fig. S3-S4) for the

827 natural and non-criminal endpoints. Bayes Factors (BF) support a hypothesis over the null when

$828>3$, support the null over a hypothesis when $<0.33$ and represent inconclusive evidence for either

829 hypothesis with $0.33<\mathrm{BF}<3$ [47]. Panel A. CIF curves show the proportion of collared wolves 
830 disappearing (LTF, yellow line) was significantly greater than other endpoints, during periods of

831 liberalized killing $(\mathrm{SHR}=2.28$, Compatible interval $=+0.38$ to $+2.76, \mathrm{p}<0.001)$. Panels B-D.

832 Lines show cumulative hazard over analysis time (days of monitoring each wolf). B. LTF HR =

8332.21 (compatible interval $=+0.36$ to +2.60$)$. C. Agency removal $\mathrm{HR}=1.05$ (Compatible

834 interval $=-0.41$ to +0.88$)$. D. Reported poached $H R=0.78($ Compatible interval $=-0.56$ to

$835+0.39)$.

836 
838 Table 5. Cox model of cause-specific hazards for each endpoint for 279 collared Mexican

839 wolves. $\mathrm{HR}<1$ represents a reduction in hazard during periods of liberalized killing (lib_kill =1)

840 and $\mathrm{HR}>1$ denotes an increase in hazard, $\mathrm{HR}<1$ a decrease, and $\mathrm{HR}=1$ no change in hazard.

841 Only the most parsimonious model is presented (Suppl. Mat. For all models), In all cases the

842 proportional hazard assumption of the Cox models was met. Comp. Int. = compatible interval

843 around point estimates.

\begin{tabular}{|c|c|c|c|c|c|c|c|c|c|c|}
\hline \multirow[b]{3}{*}{ Variable } & \multicolumn{10}{|c|}{ Endpoint } \\
\hline & \multicolumn{2}{|c|}{$\begin{array}{l}\text { Lost to follow-up } \\
\text { (LTF) }\end{array}$} & \multicolumn{2}{|c|}{$\begin{array}{l}\text { Agency } \\
\text { Removal }\end{array}$} & \multicolumn{2}{|c|}{$\begin{array}{l}\text { Reported } \\
\text { Poached }\end{array}$} & \multicolumn{2}{|c|}{ Non-Criminal } & \multicolumn{2}{|c|}{ Natural } \\
\hline & HR & $\begin{array}{l}\text { Comp. } \\
\text { Int. }\end{array}$ & HR & $\begin{array}{l}\text { Comp. } \\
\text { Int. }\end{array}$ & HR & $\begin{array}{l}\text { Comp. } \\
\text { Int. }\end{array}$ & HR & $\begin{array}{l}\text { Comp. } \\
\text { Int. }\end{array}$ & HR & $\begin{array}{l}\text { Comp. } \\
\text { Int. }\end{array}$ \\
\hline $\begin{array}{l}\text { Liberalized Killing } \\
\text { Periods (lib kill) }\end{array}$ & $2.21^{*}$ & $\begin{array}{l}1.36- \\
3.60\end{array}$ & 1.05 & $\begin{array}{l}0.59- \\
1.88\end{array}$ & 0.78 & $\begin{array}{l}0.44- \\
1.39\end{array}$ & 1.42 & $\begin{array}{l}0.75- \\
2.71\end{array}$ & 1.28 & $\begin{array}{l}0.53- \\
3.08\end{array}$ \\
\hline
\end{tabular}

$844 * \mathrm{p}<0.001$, all other results had $\mathrm{p}>0.05$ 
Table 6. Fine-Grey competing risk models of cause-specific subhazard (SHR) for each endpoint

847 for 279 collared Mexican wolves. SHR $<1$ represents a reduction in the incidence of the

848 endpoint during periods of liberalized killing (lib_kill = 1) and SHR > 1 an increase in incidence.

849 SHR = 1 would represent no change in relative incidence. Only the most parsimonious model is

850 presented (see Suppl. Mat. Comp. Int. = compatible intervals around point estimates.

\begin{tabular}{|c|c|c|c|c|c|c|c|c|c|c|}
\hline \multirow[b]{3}{*}{ Variable } & \multicolumn{10}{|c|}{ Endpoint } \\
\hline & \multicolumn{2}{|c|}{$\begin{array}{l}\text { Lost to follow- } \\
\text { up (LTF) }\end{array}$} & \multicolumn{2}{|c|}{$\begin{array}{l}\text { Agency } \\
\text { Removal }\end{array}$} & \multicolumn{2}{|c|}{$\begin{array}{l}\text { Reported } \\
\text { Poached }\end{array}$} & \multicolumn{2}{|c|}{ Non-Criminal } & \multicolumn{2}{|c|}{ Natural } \\
\hline & SHR & $\begin{array}{l}\text { Comp. } \\
\text { Int. }\end{array}$ & SHR & $\begin{array}{l}\text { Comp. } \\
\text { Int. }\end{array}$ & SHR & $\begin{array}{l}\text { Comp. } \\
\text { Int. }\end{array}$ & SHR & $\begin{array}{l}\text { Comp. } \\
\text { Int. }\end{array}$ & SHR & $\begin{array}{l}\text { Comp. } \\
\text { Int. }\end{array}$ \\
\hline $\begin{array}{l}\text { Liberalized } \\
\text { Killing } \\
\text { Periods } \\
\text { (lib_kill) }\end{array}$ & $2.28 *$ & $\begin{array}{l}1.38- \\
3.76\end{array}$ & 0.96 & $\begin{array}{l}0.53- \\
1.75\end{array}$ & 0.69 & $\begin{array}{l}0.38- \\
1.25\end{array}$ & 1.27 & $\begin{array}{l}0.66- \\
2.46\end{array}$ & 1.32 & $\begin{array}{l}0.56- \\
3.11\end{array}$ \\
\hline
\end{tabular}


853 Table 7. Bayes Factor (BF) calculations for reported poached. LTF and aggregated 'total

854 potential poached' (LTF+POA) endpoints for collared Mexican wolves using three

855 specifications; (1) a half-normal distributions using the Mexican wolf agency removal endpoint

856 point estimate of HR and SHR; (2) a uniform function using the agency removal endpoint for

857 Mexican wolves as the upper bound and 0 as the lower bound, and (3) a half normal distribution

858 and the analogous estimates of HR and SHR from Santiago-Avila et al. [19]; see Suppl. Mat. For

859 all parameters). BFs strength of evidence for each hypothesis (or null) was interpreted as

860 follows: $1 / 3<\mathrm{BF}<3$ (ref), would be inconclusive evidence; $\mathrm{BF}>3$ would represent substantial

861 evidence for the alternative hypothesis; $\mathrm{BF}<1 / 3$, would represent substantial evidence for the null

862 hypothesis of no association.

\begin{tabular}{|l|l|l|l|l|l|l|}
\hline \multicolumn{2}{|l}{} & \multicolumn{2}{l}{ Endpoint } \\
\cline { 2 - 7 } & \multicolumn{2}{l}{ LTF } & POA & \multicolumn{2}{l|}{ LTF+POA } \\
\cline { 2 - 8 } BF Specifications & HR & SHR & HR & SHR & HR & SHR \\
\hline $\begin{array}{l}\text { (1) half-normal w/MX-agency } \\
\text { removal }\end{array}$ & 1.8 & 0.69 & 0.89 & 1.14 & 1.15 & 0.76 \\
\hline $\begin{array}{l}\text { (2) uniform w/upbound-MX } \\
\text { agency removal }\end{array}$ & 1.41 & 1.30 & 0.93 & 0.92 & 1.09 & 1.19 \\
\hline \begin{tabular}{l} 
(3) half-normal w/WI POA \\
\hline
\end{tabular} & 8.08 & 8.08 & 1.25 & 1.63 & 1.35 & 0.47 \\
\hline
\end{tabular}




\section{Data Accessibility}

866 The pre-registered Stage 1 report can be found on the Open Science Framework at the following

867 link: https://osf.io/f2kmb/?view_only=28de338783724f4e96c4bede49d795d1

868 The raw datasets sources from the U.S. Fish and Wildlife Service and the Office of Law

869 Enforcement have been submitted to Dryad and can be found at the following link:

870 https://datadryad.org/stash/share/6MNn9bAx93rtciLPNSFZN0DG0cGgoI7Z-OSZ83DN2LQ

871 We have also included the prepared data in our Dryad submission which is ready to be run

872 through the STATA code included starting on p. 11 of Supplemental Materials.

873 Author Contributions

874 All authors developed the study. The stage 1 manuscript was drafted by FSA and NL, and was

875 edited and reviewed by all authors. Data analyses were conducted by FSA and NL, and

876 independent interpretation of the results was first conducted by DP and AT. Final interpretation

877 and discussion of results was conducted by all authors. The discussion was drafted by NL and

878 AT, with edits and reviews conducted by all authors. All authors have approved the final version 879 of the manuscript.

881 Acknowledgments

882 We thank the US Fish \& Wildlife Service Mexican Wolf Recovery Program and Office of Law

883 Enforcement staff, especially Maggie Dwire and John Oakleaf, for data collection, provision and

884 assistance in data interpretation. We thank Judy Calman for assistance in obtaining agency data.

885 We thank the UCLA Law School Animal Law \& Policy Grants Program and Therese Foundation 
bioRxiv preprint doi: https://doi.org/10.1101/2021.02.19.432027; this version posted February 20, 2021. The copyright holder for this preprint (which was not certified by peer review) is the author/funder, who has granted bioRxiv a license to display the preprint in perpetuity. It is made available under aCC-BY-NC-ND 4.0 International license.

886 for funding. We thank the editor and two anonymous reviewers for their helpful comments and

887 suggestions. This article does not necessarily reflect the views of the institutions or agencies

888 involved. 


\section{References}

1. Woodroffe R, Ginsberg JR. Edge Effects and the Extinction of Populations Inside

Protected Areas. Science [Internet]. 1998 Jun [cited 2020 Jan 8]; 280:2126-2128. Available from http://science.sciencemag.org/content/280/5372/2126.abstract

2. Wydeven A, Mladenoff DJ, Sickley TA, Kohn B, Thiel P, Hansen JL. Road density as a factor in habitat selection by wolves and other carnivores in the Great Lakes region. Endangered Species Update [Internet]. 2001 [cited 2020 Jan 8]; 18(4):110-114.

Available from

\section{https://pdfs.semanticscholar.org/ffc8/2dbae01f91009758343c0cdd6c6edeb9d573.pdf}

3. Treves A, Chapron G, López-Bao J V, Shoemaker C, Goeckner AR, Bruskotter JT. Predators and the public trust. Biol. Rev. [Internet]. 2017 Nov [cited 2020 Jan 8]; 92(1): 248-270. Available from https://doi.org/10.1111/brv.12227

4. Treves A, Artelle KA, Darimont CT, Parsons DR. Mismeasured mortality: correcting estimates of wolf poaching in the United States. J Mammal [Internet]. 2017 Oct [cited 2020 Jan 8]; 98(5): 1256-1264. Available from https://doi.org/10.1093/jmammal/gyx052

5. Treves A, Langenberg JA, López-Bao J V., Rabenhorst MF. Grey wolf mortality patterns in Wisconsin from 1979 to 2012. J Mammal [Internet]. 2017 Feb [cited 202 Jan 8]; 98(1):17-32. Available from 573http://dx.doi.org/10.1093/jmammal/gyw145

6. Ripple WJ, Estes JA, Beschta RL, Wilmers CC, Ritchie EG, Hebblewhite M, Berger J, Elmhagen B, Letnic M, Nelson MP et al. Status and ecological effects of the world's largest carnivores. Science [Internet]. 2014 Jan [Cited 2020 May 19]; 343 (6167); 1241484. Available from https://science.sciencemag.org/content/343/6167/1241484.full 
7. Liberg O, Chapron G, Wabakken P, Pedersen HC, Hobbs NT, Sand H. Shoot, shovel and shut up: cryptic poaching slows restoration of a large carnivore in Europe. P Roy Soc BBiol Sci [Internet]. 2012 Mar [cited 2020 Jan 8]; 279:910-915. Available from http://www.ncbi.nlm.nih.gov/pubmed/21849323

8. Suutarinen J, Kojola I. Poaching regulates the legally hunted wolf population in Finland. Biol Conserv [Internet]. 2017 [cited 2020 Jan 8]; 215:11-18. Available from http://www.sciencedirect.com/science/article/pii/S0006320717302148

9. Humane Society of the U.S. et al. v Dirk Kempthorne, Secretary of the Interior, et al. (2006). 481 F. Supp. 2d 53 (DDC 2006)

10. Treves A. Hunting for large carnivore conservation. J Appl Ecol [Internet]. 2009 Nov [cited 2020 Jan 8]; 46(6):1350-5641356. Available from https://doi.org/10.1111/j.13652664.2009.01729.x

11. Olson ER, Stenglein JL, Shelley V, Rissman AR, Browne-Nuñez C, Voyles Z, et al. Pendulum swings in wolf management led to conflict, illegal kills, and a legislated wolf hunt. Conserv Lett [Internet]. 2015 Sept [cited 2020 Jan 8]; 8(5): 351-360. Available from https://doi.org/10.1111/conl.12141

12. Treves A, Naughton-Treves L, Shelley V. Longitudinal analysis of attitudes toward wolves. Conserv Biol [Internet]. 2013 Apr [cited 2020 Jan 8]; 27(2):315-323. Available from http://www.ncbi.nlm.nih.gov/pubmed/23293913

13. Browne-Nuñez C, Treves A, MacFarland D, Voyles Z, Turng C. Tolerance of wolves in Wisconsin: A mixed-methods examination of policy effects on attitudes and behavioral inclinations. Biol Conserv [Internet]. 2015 Sept [cited 2020 Jan 8]; 189: 59-71 Available from https://doi.org/10.1016/j.biocon.2014.12.016 
14. Hogberg J, Treves A, Shaw B, Naughton-Treves L. Changes in attitudes toward wolves

935

936

937

938

939

940

941

942

943

944

945

946

947

948

949

950

951

952

953

954

955

before and after an inaugural public hunting and trapping season: early evidence from

Wisconsin's wolf range. Environ Conserv [Internet]. 2015 May [cited 2020 Jan 8]; 43(1):

45-55. Available from https://doi.org/10.1017/S037689291500017X

15. Chapron G, Treves A. Blood does not buy goodwill: allowing culling increases poaching of a large carnivore. P Roy Soc B-Biol Sci [Internet]. 2016 May [cited 2020 Jan 8]; 283(1830): 20152939. Available from http://rspb.royalsocietypublishing.org/content/royprsb/283/1830/20152939.full.pdf

16. Chapron G, Treves A. Correction to 'Blood does not buy goodwill: allowing culling increases poaching of a large carnivore.' P Roy Soc B-Biol Sci [Internet]. 2016 [cited 2020 Jan 8]; 283(1845): 20162577. Available from http://rspb.royalsocietypublishing.org/lookup/doi/10.1098/rspb.2016.2577

17. Chapron G, Treves A. Reply to comments by Olson et al. 2017 and Stien 2017. P Roy Soc B-Biol Sci [Internet]. 2017 [cited 2020 Jan 8]; 284: 20171743. Available from http://rspb.royalsocietypublishing.org/content/royprsb/284/1867/20171743.full.pdf

18. Stenglein JL, Zhu J, Clayton MK, Van Deelen TR. Are the numbers adding up? Exploiting discrepancies among complementary population models. Ecol Evol. 2015 Jan [cited 2020 Jan 8]; 5(2): 368-553376. Available from http://dx.doi.org/10.1002/ece3.1365

19. Santiago-Ávila FJ. An interdisciplinary evaluation of large carnivore management: the grey wolf in the Western Grey Lakes [PhD dissertation]. University of WisconsinMadison; 2019. 
20. Suutarinen J, Kojola I. One way or another: predictors of wolf poaching in a legally harvested wolf population. Anim Conserv [Internet]. 2018 [cited 2020 Jan 8]; 21(5):1-9. Available from https://doi.org/10.1111/acv.12409

21. Liberg O, Suutarinen J, Akesson M, Andren H, Wabakken P, Wikenros C, Sand H. $\underline{\text { Poaching-related disappearance rate of wolves in Sweden was positively related to }}$ population size and negatively to legal culling. Biol Conserv [Internet]. 2020 Mar [Cited 2020 May 19]; 243: 108456. Available from https://www.sciencedirect.com/science/article/abs/pii/S0006320719311498

22. Treves A, Louchouarn N, Santiago-Avila S. Response to Liberg et al. 2020: Modelling concerns confound evaluations of legal wolf-killing. Biol Conserv. In Review.

23. Chapron G, Treves A. Reply to comment by Pepin et al. 2017. P Roy Soc B-Biol Sci [Internet]. 2017 Mar [cited 2020 Jan 8]; 284(1851): 20162571. Available from http://rspb.royalsocietypublishing.org/content/royprsb/284/1851/20162571.full.pdf.

24. Refsnider RL. The role of the Endangered Species Act in Midwest wolf recovery. In: Wydeven AP, Van Deelan TR, Heske E, editors. Recovery of grey wolves in the Great Lakes Region of the United States. New York: Springer; c2009. p. 311-329

25. US Fish and Wildlife Service [Internet]. Mexican Wolf Recovery Efforts; 2019 Apr 8 [cited 2020 Jan 8]. Available from https://www.fws.gov/southwest/es/mexicanwolf/Recovery.html 26. Wydeven AP, Treves A, Brost B, Wiedenhoeft JE. Characteristics of wolf packs in Wisconsin: identification of traits influencing depredation. In: People and Predators: From Conflict to Coexistence. Washington, DC: Island Press; c2004. p. 28-50 
27. Mladenoff DJ, Clayton MK, Pratt SD, Sickley TA, Wydeven AP. Change in occupied wolf habitat in the northern Great Lakes region. In: Wydeven AP, Van Deelan TR, Heske E, editors. Recovery of grey wolves in the Great Lakes Region of the United States. New York: Springer; c2009. p. 119-138

28. Ruid DB, Paul WJ, Roell BJ, Wydeven AP, Willging RC, Jurewicz RL, Lonsway DH. Wolf-human conflicts and management in Minnesota, Wisconsin, and Michigan. In: Wydeven AP, Van Deelan TR, Heske E, editors. Recovery of grey wolves in the Great Lakes Region of the United States. New York: Springer; c2009. p. 279-295

29. Thiel RP, Hall W, Heilhecker E, Wydeven AP. An Isolated Wolf Population in Central Wisconsin. In: Wydeven AP, Van Deelan TR, Heske E, editors. Recovery of grey wolves in the Great Lakes Region of the United States. New York: Springer; c2009. p. 107-117

30. Wydeven AP, Wiedenhoeft JE, Schultz RN, Thiel RP, Jurewicz RL, Kohn BE, Van Deelen TR. History, population growth, and management of wolves in Wisconsin. In: Wydeven AP, Van Deelan TR, Heske E, editors. Recovery of grey wolves in the Great Lakes Region of the United States. New York: Springer; c2009. p 87-105

31. Fitzgerald EA. The Lobo Limps on from Limbo: A History, Summary, and Outlook for Mexican Wolf Recovery in the American Southwest. Colo. Nat. Resources, Energy \& Envtl. L. Rev [Internet]. 2018 [cited 2020 Jan 8]; 29(3): 223-284. Available from https://www.colorado.edu/law/sites/default/files/attachedfiles/fitzgerald_online_copy.pdf

32. Schmidt JH, Johnson DS, Lindberg MS, Adams LG. Estimating demographic parameters using a combination of known-fate and open N-mixture models. Ecology [Internet]. 2015 
Oct [cited 2020 Jan 8]; 56: 2583-2589. Available from:

\section{https://esajournals.onlinelibrary.wiley.com/doi/10.1890/15-0385.1}

33. Stenglein JL, Wydeven AP, Van Deelen TR. Compensatory mortality in a recovering top carnivore: wolves in Wisconsin, USA (1979-2013). Oecologia [Internet]. 2018 [cited 2020 Jan 8]; 187: 99-111. Available from https://doi.org/10.1007/s00442-018-4132-4

34. Concato J, Peduzzi P, Holford TR, Feinstein AR. 1995. Importance of Events per Independent Variable in Proportional Hazards Analysis I. Background, Goals and General Strategy. J Clinical Epidemiol [Internet]. 1995 [cited 2020 Feb 25]; 48 (12): 1495-1501. Available from https://www.ncbi.nlm.nih.gov/pubmed/8543963

35. Peduzzi P, Concato J, Feinstein AR, Holford TR. Importance of Events per Independent Variable in Proportional Hazards Regression Analysis II. Accuracy and Precision of Regression Estimates. J Clinical Epidemiol [Internet]. 1995 [cited 2020 Feb 25]; 48 (12): 1503-1510. Available from https://www.ncbi.nlm.nih.gov/pubmed/8543964

36. Vittinghoff E, Mcculloch CE. Original Contribution Relaxing the Rule of Ten Events per Variable in Logistic and Cox Regression. Am J Epidemiol [Internet]. 2007 [cited 2020 May 18]; 165 (6): 710-18. https://doi.org/10.1093/aje/kwk052

37. Putter H, Fiocco M, Geskus RB. 2007. Tutorial in biostatistics: competing risks and multi-state models. Stat Med. 2007 Oct [cited 2020 Jan 8]; 26(11): 2389-2430.

38. Kalbfleisch JD, Prentice RL. The statistical analysis of failure time data. 2nd edn. Hoboken, NJ: Wiley, 2002c.

39. Heisey DM, Patterson BR. A Review of Methods to Estimate Cause-Specific Mortality in Presence of Competing Risks. J Wildlife Manage [Internet]. 2006 [cited 2020 Jan 8]; 70:1544-1555. Available from http://www.jstor.org/stable/4128086 
1023

1024

1025

1026

1027

1028

1029

1030

1031

1032

1033

1034

1035

1036

1037

1038

1039

1040

1041

1042

1043

1044

40. Hosmer Jr DW, Lemeshow S, May S. Applied survival analysis: Regression modelling of time to event data. 2nd edn. Hoboken, New Jersey, USA: Wiley-Interscience, c2008.

41. Austin PC, Lee DS, Fine JP. Introduction to the Analysis of Survival Data in the Presence of Competing Risks. Circulation [Internet]. 2016 [cited 2020 Jan 8]; 133: 601-609. Available from http://circ.ahajournals.org/content/circulationaha/133/6/601.full.pdf

42. Dignam JJ, Kocherginsky MN. Choice and Interpretation of Statistical Tests Used When Competing Risks Are Present. J Clin Oncol [Internet]. 2008 [cited 2020 Jan 8]; 26:40274034. Available from http://www.ncbi.nlm.nih.gov/pmc/articles/PMC2654314/

43. Fine JP, Gray RJ. A proportional hazards model for the sub-distribution of a competing risk. J American statistical Association [Internet]. 1999 [cited 2020 Jan 8]; 94:496-509. Available from https://amstat.tandfonline.com/doi/abs/10.1080/01621459.1999.10474144\#.XhZmVfyIb $\underline{\mathrm{U}}$

44. Dignam JJ, Zhang Q, Kocherginsky MNM. The Use and Interpretation of Competing Risks Regression Models. Clin Cancer Res [Internet]. 2012 [cited 2020 Jan 8]; 18:23012308. Available from http://www.ncbi.nlm.nih.gov/pmc/articles/PMC3328633/

45. Austin PC, Allignol A, Fine JP. The Number of Primary Events per Variable Affects Estimation of the Subdistribution Hazard Competing Risks Model. J Clin Epidemiol [Internet]. 2017 [cited 2020 Feb 25]; 83: 75-84. Available from https://doi.org/10.1016/j.jclinepi.2016.11.017

46. Latouche A, Allignol A, Beyersmann J, Labopin M, Fine JP. A competing risks analysis should report results on all cause-specific hazards and cumulative incidence functions. $\mathbf{J}$ 
Clin Epidemiol [Internet]. 2013 [cited 2020 Jan 8]; 66:648-653. Available from

1046

1047

1048

1049

1050

1051

1052

1053

1054

1055

1056

1057

1058

1059

1060

1061

1062

1063

1064

1065

1066

1067

http://dx.doi.org/10.1016/j.jclinepi.2012.09.017

47. Dienes Z. Using bayes to get the most out of non-significant results. Front Psychol

[Internet]. 2014 [cited 2020 May 18]; 5: 781. Available from:

https://www.ncbi.nlm.nih.gov/pmc/articles/PMC4114196/

48. Dienes Z. How do I know what my theory predicts? Advances in Methods and Practices in Psychological Science [Internet]. 2019 [cited 2020 Jun 25]; 2(4): 364-377. Available from: https://doi.org/10.1177/2515245919876960.।

49. Agan S. The human dimensions and spatial ecology of poaching and implications for red wolf survival [Dissertation]. New Hampshire: Antioch New England Graduate School; 2020. $181 \mathrm{p}$.

50. U.S. Fish and Wildlife Service. Mexican wolf recovery: progress report \#21.

Albuquerque; U.S. Fish and Wildlife Service Southwest Region; 2018. 71 p. Progress

Report No.: 21.

51. Frazer G. Letter to California Fish and Game Commission in response to

FWS/AES/DCC/BDFS/073807. 2020 Dec 14. Washington, D.C.: U.S. Fish and Wildlife Service. 4 pp.

52. Anderson G. Mexican wolf killings expose a dark underbelly of Western culture. Wildlife News [Internet]. 2020 Dec 21 [cited 2020 Dec 23]. Available from:

http://www.thewildlifenews.com/2020/12/21/mexican-wolf-killings-expose-a-darkunderbelly-of-western-culture/

53. Platt JR. Strong inference. Science [Internet]. 1964 [cited 2020 Dec 18]; 146(3642): $347-$ 353. Available from: https://science.sciencemag.org/content/146/3642/347 
1068

1069

1070

1071

1072

1073

1074

1075

1076

1077

1078

1079

1080

1081

1082

1083

1084

1085

1086

1087

1088

1089

54. Ioannidis JPA. Why most published research findings are false. PLoS Med [Internet]. 2005 [cited 2020 Dec 18]; 2(8): e124. Available from: https://doi.org/10.1371/journal.pmed.0020124

55. Treves A, Krofel M, McManus J. Predator control should not be a shot in the dark. Front Ecol Environ [Internet]. 2016 [cited 202 Dec 18]; 14(7): 1-9. Available from: https://doi.org/10.002/fee.1312

56. Treves A, Krofel M, Ohrens O, van Eeden LM. Predator control needs a standard of unbiased randomized experiments with cross-over design. Front Ecol Environ [Internet]. 2019 [cited 2020 Dec 18]; 7(462). Available from:

https://doi.org/10.3389/fevo.2019.00462

57. van Eeden LM, Eklund A, Miller JRB, Lopez-Bao JV, Chapron G, Cejtin MR, et al. Carnivore conservation needs ecidence-based livestock protection. PLOS Biol [Internet]. 2018 [cited 2020 Dec 18]; 16(9): e2005577. Available from: https://doi.org/10.1371/journal.pbio.2005577

58. Ctr. for Biological Diversity v. Jewell, No. CV-15-00019-TUC-JGZ (1) (D. Ariz. Mar. 30, 2018).

59. Bruskotter JT, Vucetich JA, Slagle KM, Berardo R, Singh AS, Wilson RS. Support for the U.S. Endangered Species Act over time and space: Controversial species do not weaken public support for protective legislation. Conserv Letters [Internet]. 2018 [cited 2020 Dec 18]; e12595: 1-7. Available from: https://doi.org/10.1111/conl.12595

60. U.S. Fish and Wildlife Service. Mexican wolf population rises to at least 163 animals [Press Release]. Phoenix: U.S. Fish and Wildlife Service; 2020 Mar 18 [cited 2020 Dec 
18]. https://www.fws.gov/news/ShowNews.cfm?ref=mexican-wolf-population-rises-toat-least-163-animals-\& ID=36531

1092

1093

1094

1095

1096

1097

1098

1099

1100

1101

1102

1103

1104

1105

1106

1107

1108

1109

1110

1111

61. Atkins North America, Inc. Summary report of independent peer review for the U.S. Fish and Wildlife Service gray wolf delisting review. Tampa: Atkins North America, Inc; 2019. $245 \mathrm{p}$.

62. Treves, A. (2020). Memo: RIN:1018-BD60 proposed rule to remove federal protections for gray wolves nationwide. Office of Management and Budget Office of Information and regulatory Affairs, 29 sep 2020 (telecommuting: list if attendees: Maricela Constantino - DOI Teleconference; Sean Gallagher - DOI Teleconference; Bivan Patnaik - DOI Teleconference; Kristen Floom - DOI Teleconference; Austin Mudd OIRA Teleconference; Maureen Trnka - OIRA Teleconference; Julie Hewitt - OIRA Teleconference; Matthew Oreska - OMB Teleconference; Ellen VanGelder - DOI Teleconference; Dr. Adrian Treves - University of Wisconsin - Madiso

63. Kalternborn BP, Brainerd SM. Can poaching inadvertently contribute to increased public acceptance of wolves in Scandinavia? Eur J Wildlife Res [Internet]. 2016 [cited 202 Dec 18]; 62: 179-188. Available from: https://link.springer.com/article/10.1007/s10344-016$\underline{0991-3}$

64. Haas TC, Ferreira SM. Combating rhino horn trafficking: the need to disrupt criminal networks. PLOS One [Internet]. 2016 [cited 2020 Dec 18]; 11(11): e0167040. Available from: https://www.ncbi.nlm.nih.gov/pmc/articles/PMC5117767/

65. Biggs D, Cook C, Redford K, Holden MH. How to overcome fierce debates about banning all trade in ivory. The Conversation [Internet]. 2018 [cited 2020 Dec 18]. 
Available from: https://theconversation.com/how-to-overcome-fierce-debates-aboutbanning-all-trade-in-ivory-95318 European Union and United States. RECIEL [Internet]. 2017 [cited 2020 Dec 18]; 26(1): 19-29. Available from: http://onlinelibrary.wiley.com/wol1/doi/10.1111/reel.12188/abstract management. Wildlife Soc B [Internet]. 2002 [cited 2020 Dec 18]; 30(4): 1287-1292. Available from: https://www.jstor.org/stable/3784302 hunting on the population dynamics of an African lion population in a protected area. Biol Conserv [Internet]. 2007 [cited 2020 Dec 18]; 134(4): 548-558. Available from: 